\title{
Relation between all cause standardised mortality ratios and two indices of deprivation at regional and district level in England
}

\author{
NICHOLAS MAYS AND SUSAN CHINN
}

From the Department of Community Medicine, United Medical and Dental Schools of Guy's and St Thomas's Hospitals, St Thomas' Campus, London.

ABSTRACT The use of mortality data in the form of standardised mortality ratios (SMRs) to measure the need for health care resources in the Resource Allocation Working Party (RAWP) formula in England has been criticised for underestimating the wider effects of adverse socioeconomic conditions on need, particularly in inner city areas. To assess this criticism, we explored the relationships at NHS Regional and District levels in England between two indicators of illness from the 1981 Census, two contrasting indices of deprivation based on the 1981 Census (the Jarman 8 Underprivileged Area (UPA) score and Townsend's Index of Material Deprivation) and their constituent variables, and all cause SMRs for 1982-3. All cause SMRs were highly correlated at Regional and District level with permanent and temporary sickness rates. At Regional level, three of the Thames Regions showed relatively high deprivation scores in relation to their SMRs, in comparison to the remaining Regions where the relative level of deprivation closely matched the Region's mortality ranking. District level analyses of the relations between SMRs and the deprivation indices and their constituent variables showed that the Thames/non-Thames dichotomy was accounted for by the 14 Districts in inner London. These findings suggest that although there may be a prima facie case for including an allowance for deprivation in RAWP, it is still not clear how the deprivation variables available in the Census relate empirically to the need for additional health service resources. The analysis raises questions about the appropriate definition of need in this context and whether the Census is a suitable source for the construction of a deprivation weighting for use in national RAWP.

The Resource Allocation Working Party (RAWP) national formula is used to calculate the fair share of National Health Service (NHS) revenue (the resource "target") for hospital and community health services which each of the 14 Regional Health Authorities (RHA) in England should receive. ${ }^{1}$ Annual allocations are gradually moved towards target values by the Department of Health and Social Security to achieve an equitable distribution of funds. Analogous formulas, varied in response to local circumstances and data availability, operate below Regional level and determine allocations to District Health Authorities (DHA). Similar formulas operate in the other constituent countries of the United Kingdom. The national RAWP formula uses mortality data in the form of standardised mortality ratios (SMRs) to account for variations in the need for health care resources, defined in terms of relative morbidity, which remain after the size and age/sex structure of the population in each Region have been taken into account. The adequacy of mortality data as a proxy for morbidity and thereby for need has been criticised continuously since RAWP was first implemented in 1977/78.

RAWP chose to use mortality rates for a variety of practical reasons such as their annual production, accuracy and availability at all levels of the Health Service, but also because they were independent of the existing unequal supply of health service resources. The Working Party also had evidence from its own analyses that mortality rates correlated well with the limited range of available morbidity data (eg, sickness absence rates and self reported illness rates from the General Household Survey) at RHA level. RAWP argued that morbidity rates would, in turn, reflect the socioeconomic and environmental conditions in an area, since adverse conditions were known to increase the susceptibility to disease and death. The RAWP 
analyses showed that SMRs were highly correlated with a number of indicators associated with deprived and lower social class areas (eg, early termination of education, unemployment and public housing) ${ }^{2}$ Like SMRs, these indicators tended to have high values in northern Metropolitan Districts. The validity of mortality rates as indicators of relative population morbidity has been questioned in a number of studies. $^{3-5}$ The use of SMRs in RAWP has also been criticised for understating the additional needs of socially deprived areas. ${ }^{267}$ However, other studies have produced results which support the use of mortality data, both as a morbidity proxy ${ }^{8}$ and as an indicator of adverse socioeconomic conditions likely to be associated with additional needs. ${ }^{9-11} \mathrm{~A}$ recent review of the literature on the needs weightings in RAWP concluded that the case against the use of mortality rates was as yet unproven. ${ }^{12}$ However, the question remains: is there a case for taking account of deprivation in the RAWP formula on the grounds that not all the needs associated with adverse socioeconomic conditions are necessarily reflected in morbidity or mortality rates? This question formed an important part of the recently completed NHS Management Board review of national RAWP. ${ }^{13} 14$ In addition to its impact on levels of disease, deprivation may affect the need for resources in at least three other ways: by reducing accessibility to services, as in the case of people too poor to own a car; by increasing resource utilisation for each treated condition; and by adversely affecting the outcomes of health care (eg, by increasing postoperative complication rates). ${ }^{15}$ For example, it may be argued that the use of SMRs alone in the RAWP formula may understate the resource requirements of health authorities in deprived areas if elderly patients have to stay in hospital longer in order to be fit enough to return to poor housing conditions. RAWP was concerned, in contrast to this approach, to avoid distorting the resource allocation process for health services by reference to socioeconomic conditions which health services were poorly placed to ameliorate.

The RAWP review has recommended including an allowance for deprivation in the national formula on the basis of an analysis of the determinants of hospital use in small areas. ${ }^{14}$ The analysis reported in this paper seeks to contribute to the ensuing debate about the appropriate need indicators for inclusion in RAWP by exploring the relation at RHA and DHA levels in England between all cause SMRs and routinely available indicators of morbidity and deprivation. The research for this paper describes the relations at RHA and DHA levels between all cause SMRs and (1) morbidity rates, (2) deprivation scores, and (3) individual variables used in constructing deprivation indices.
The analysis provides an indication as to whether the relative needs of any parts of the country are likely to be systematically underrepresented in the RAWP formula. There is particular concern about whether the use of SMRs alone adequately reflects the needs of inner London. ${ }^{2}$ In addition, the analysis allows a comparison to be made between the behaviour of different measures of deprivation in relation to SMRs, with a view to suggesting which, if any, might be included in the national RAWP formula. The results also update earlier studies which were based on the 1971 Census ${ }^{699}$ and include measures of deprivation not previously available. ${ }^{11} 16$ Whereas the research undertaken for the RAWP review was based on utilisation data, this study has avoided using data dependent on the prevailing pattern and supply of facilities rather than on variations in need. ${ }^{17}$

\section{Methods}

\section{MORTALITY}

All cause, all age SMRs for Regional and District $\vec{\omega}$ Health Authorities in England were calculated for the $N$ two years 1982 and 1983 combined, using mortalit $\vec{\phi} \overrightarrow{0}$ data from OPCS SD-25 returns. Populatio denominators were from 1982 and 1983 OPCS population estimates. It was decided to calculate at cause SMRs rather than the ICD Chapter Specifig SMRs used in the non-psychiatric inpatient (NPIPY component of the national RAWP formula, for three $\overrightarrow{0}$ reasons: (1) in sub-Regional RAWP, all cause SMR tend to be used throughout the formula; (2) the use of ICD Chapter specific SMRs in the NPIP component of the national RAWP formula implies an unjustified link between the mortality rate for a condition and the need for resources to treat that condition; and (3) the SMRs were to be analysed in relation to global indicators of morbidity and deprivation so a comprehensive measure of mortality was more appropriate.

\section{MORBIDITY}

In the absence of any other population morbidity statistics available at both RHA and DHA level, morbidity rates for the age group 16 years and over were derived from the two variables of permanent sickness and temporary sickness available in the 1981 Census. General Household Survey statistics on self reported acute and chronic sickness are not available below Regional level. The two Census morbidity proxies are defined as "permanently sick and therefore not seeking employment" and "temporarily sick and therefore unemployed". The Census data on permanent and temporary sickness were not specifically designed to measure population health status and they apply to a relatively small proportion 
of the population. They can be used reliably only for the working age population (16-64 years) and have the disadvantage of being related to the employment structure of an area. For example, they may not represent patterns of morbidity among women in a spatially consistent way. Nonetheless, they do tend to represent relatively severe forms of morbidity relevant to the need for formal health service intervention.

\section{DEPRIVATION}

Two indices of deprivation and their constituent variables were derived from the 1981 Census Small Area Statistics. The indices of deprivation were the Jarman 8 Underprivileged Area (UPA) Score ${ }^{1618}$ and Townsend's Index of Material Deprivation. ${ }^{11}$ Jarman's UPA Score was designed as an empirical measure of general practitioners' perceptions of the effect of a range of Census socioeconomic variables on their pressure of work. It has since been widely canvassed as a possible proxy measure of need for hospital and community health service resource allocation despite the fact that it was devised as a measure of perceived demand for general practitioner (GP) services. The score consists of eight Census variables derived and weighted following a survey of a sample of United Kingdom GPs. GPs were asked to weight a list of Census variables according to the degree to which they were perceived to increase the demand for their services. The UPA score was then compiled from the sum of the weighted values of each of the variables most frequently mentioned. The variables with their relative weights are given in the table.

Table Jarman 8 Underprivileged Area Score: variables and weights

\begin{tabular}{ll}
\hline Variable & Weight \\
\hline Elderly living alone & 6.62 \\
Under fives & $4 \cdot 64$ \\
Unskilled (socioeconomic group 11) & $3 \cdot 74$ \\
Unemployed & $3 \cdot 34$ \\
Single parent & 3.01 \\
Overcrowding & $2 \cdot 88$ \\
Moved house in last year & 2.68 \\
Ethnic minorities (New Commonwealth and Pakistan) & $2 \cdot 50$ \\
\hline
\end{tabular}

The Townsend Index of Material Deprivation represents a theoretical design in which four equally weighted variables, explicitly chosen to act as proxies for various aspects of a lack of control over material resources, are combined into a single score. The four variables are: unemployed, no car, overcrowding, and not being an owner-occupier of a home. Unemployment was selected as a surrogate for a general lack of material resources; no car as representing a low current income; overcrowding as a proxy for inadequate living conditions; and not being an owner-occupier as an indicator of an absence of wealth and of low income in the past. The Townsend index was chosen for analysis in this study because in comparison with the Jarman 8 UPA score it embodies a very different concept of deprivation and approach to deriving an index, yet it relies on using routine data from the Census.

The relations were examined, using scatter diagrams, between all cause SMRs and permanent and temporary sickness rates, the two indices of deprivation, and the ten individual Census socioeconomic variables, in turn, at both RHA and DHA levels. Correlation coefficients were calculated where appropriate. The principal results are summarised below.

\section{Results}

All cause SMRs and permanent and temporary sickness rates were found to be highly correlated at both RHA and DHA levels. The correlation coefficients for the four sets of relations were in the range $0.75-0.85$, implying that SMRs were a reasonable proxy for these two, admittedly, imperfect measures of morbidity. Figure 1 shows the scatter plot for all cause SMR and the percentage permanently sick for the 14 NHS Regions.

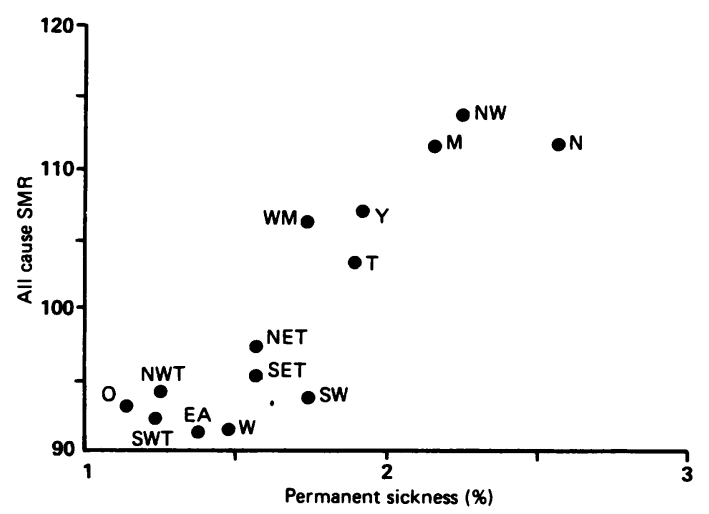

Fig 1 Plot of relation at Regional level between all cause, all age SMRs (1982/83) and percentage permanently sick from the 1981 Census

Key to NHS Regions:

$N=$ Northern

$M=$ Mersey

$N W=$ North Western

$Y=$ Yorkshire

$W M=$ West Midlands

$T=$ Trent

$W=$ Wessex
$O=O x$ ford

$E A=$ East Anglia

NET $=$ North East Thames

$N W T=$ North West Thames

$S E T=$ South East Thames

$S W T=$ South West Thames

$S W=$ South Western 
Regional analysis of the relations between all cause SMRs and the two deprivation indices (Jarman 8 UPA Score and Townsend Index) demonstrated a distinct split between three of the four Thames Regions (North West, North East and South East Thames) and the remainder of the country. For example, the Regional plot of all cause SMR against the Jarman 8 UPA score (fig 2) shows that these three Thames Regions have relatively high deprivation scores in relation to their

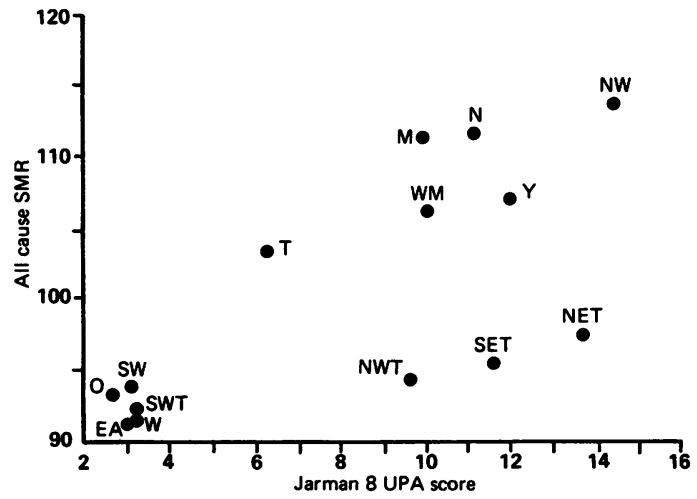

Fig 2 Plot of relation at Regional level between all cause, all age SMRs (1982/83) and Jarman 8 Underprivileged Area (UPA) Scores

SMRs in comparison to the remaining 10 Regions, where the relative level of deprivation closely matches the Region's mortality ranking. Thus the Thames RHAs have consistently higher deprivation scores than would be expected if their SMRs had the same relationships observed in the Regions to the north and west of the country. The starkest contrast in fig 2 is between the North East Thames Region and North Western Region. Their Jarman 8 UPA scores are very similar, but their all cause SMRs are 97 and 114 respectively. The scatter plot for all cause SMR and the Townsend index is virtually identical. Analysis of the two deprivation indices and SMRs at District level demonstrates that the Thames/non-Thames dichotomy is an effect caused by the 14 Districts in inner London rather than the Districts in the remainder of the Thames Regions. Without inner London, the correlation between SMR and the two measures of deprivation is very high. Figure 3 shows the results for all Districts for all cause SMRs and the Townsend index. The difference in SMR between the 14 inner London Districts and the rest, adjusting for their scores on the Townsend index, is $-17 \cdot 40$ (SE $2 \cdot 10)$. The difference adjusting for their Jarman 8 UPA scores is - 15.57 (SE 2.75).

Further analyses were undertaken to see whether the inner London effect observed for the indices of

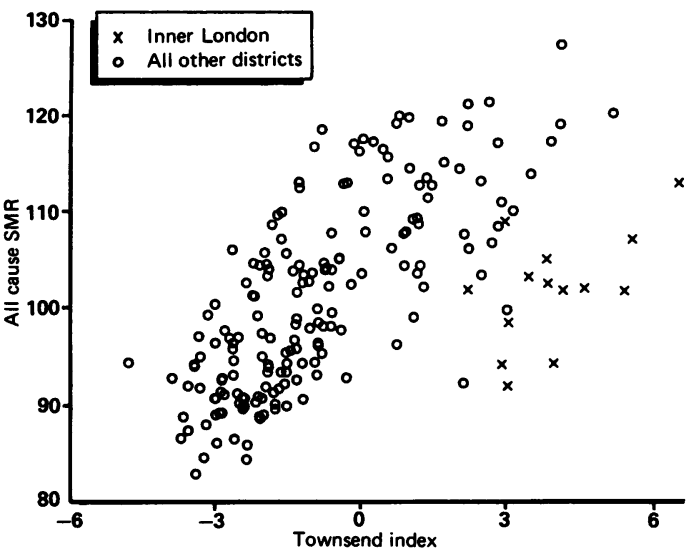

Fig 3 Plot of relation at District level between all cause SMRs and Townsend Index of material deprivation

deprivation applied equally to individual deprivation variables. Analysis of the relation between all cause $\vec{\omega}$ SMRs and the individual Census variables from which iv the Jarman and Townsend indices are constructe $\overrightarrow{0}$ shows that all but three of the 10 variables show a cleap Thames/non-Thames split in the Regional analysio The relation between all cause SMR and the Jarma single parent families variable in fig 4 is typical of the pattern observed at Regional level for the variables i

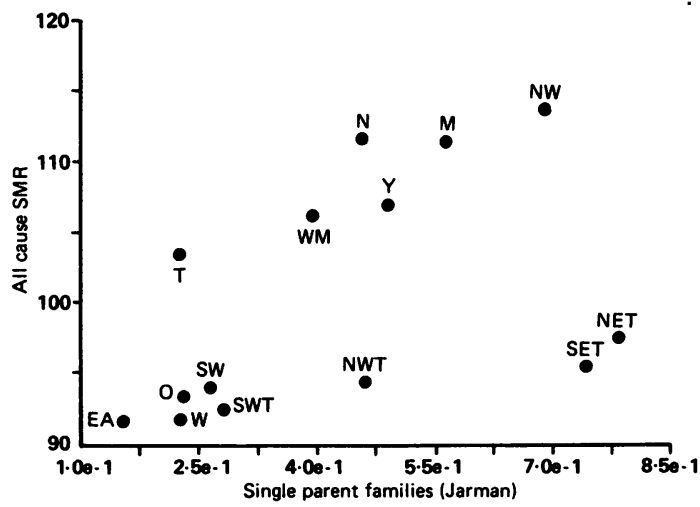

Fig 4 Plot of relation at Regional level between all cause SMRs and proportion of single parent families (as defined in Jarman 8)

the Jarman 8 UPA score, with the exception of $\bar{N}$ unemployment and the proportion of unskilled workers. At the RHA level of analysis, unemployment $\mathbb{O}$ (Jarman and Townsend), the proportion unskilled $\mathrm{C}^{N}$ (Jarman), and households without a car (Townsend), show strong, linear relationships with all cause SMRs, 
in contrast to the other seven deprivation variables analysed (overcrowding, elderly living alone, under fives, single parent families, changed address in last 12 months, ethnic minorities and non-owner occupation). The same three variables (unemployment, proportion unskilled and no car) also show strong linear relationships at RHA level with the two Census morbidity indicators of permanent and temporary sickness (correlation coefficients $>0 \cdot 8$ ).

At DHA level, the marked dichotomy between inner London and the remainder of the Districts is clearly observed for all the variables in the Jarman 8 UPA score and the Townsend Index of material deprivation. The sole exception at this level is unemployment, the scatter plot for which is shown in fig 5. With SMRs and unemployment, there is only the hint of a divergence between inner London and the

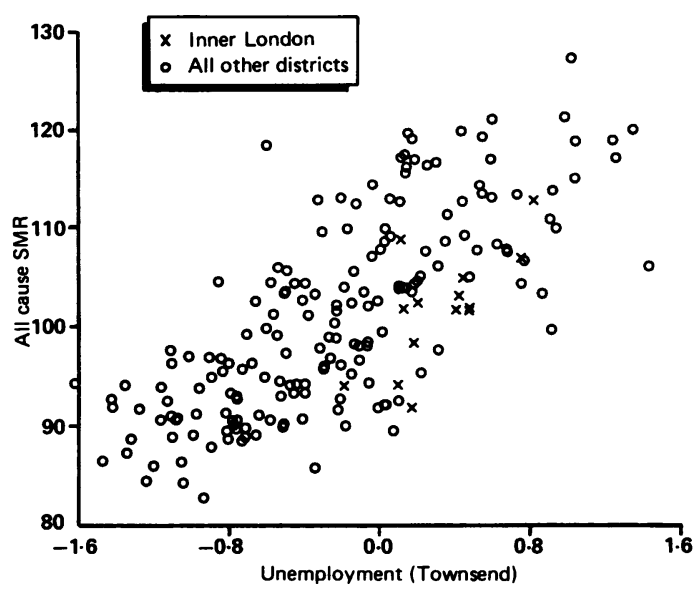

Fig 5 Plot of relation at District level between all cause SMRs and the proportion unemployed (as defined in the Townsend Index)

other Districts in the country. In contrast, for single parent families, change of address, ethnic minorities, no car and non-owner occupation, inner London Districts show particularly high values in relation to their SMRs. As an example, fig 6 shows the scatter plot for all cause SMRs and the overcrowding variable from the Jarman 8 UPA score (people in households living with more than one person per room).

\section{Discussion}

The analysis of the relationship between mortality and social indices presented in this paper can only describe the association between variables. It cannot prove or disprove the wisdom of the original selection of SMRs by RAWP. Since need itself is always a source of

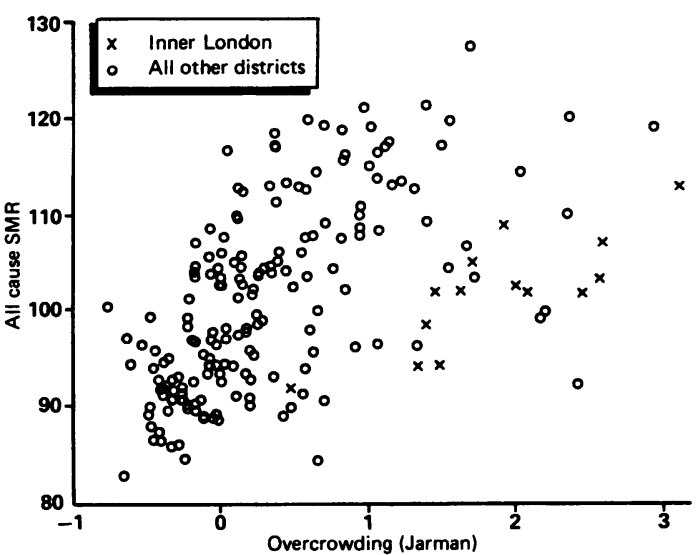

Fig 6 Plot of relation at District level between all cause SMRs and overcrowded households (as defined in Jarman 8)

controversy and cannot be measured directly, the debate is bound to centre on the relative merits of proxies. Nonetheless the results show, firstly, that the use of all cause SMRs, both at Regional and District levels, as a morbidity proxy appears to be reasonable in that there was a high degree of correlation between Census permanent and temporary sickness rates and all cause SMRs. Although the sickness variables available from the Census are incomplete measures of population morbidity and are affected by the employment structure of an area, the Regional gradient of Census sickness rates is very similar to the geographical pattern of subjective health between standard Regions observed in a recent large scale national health survey, ${ }^{19}$ implying that the Census measures do reflect genuine differences in population health status.

The analysis of the relation between all cause SMRs and two deprivation indices both at Regional and District level provides grounds for the view that the health care needs of inner London associated with adverse social conditions may be underrepresented in a RAWP formula based on SMRs alone. The inpatient bed use Census of the North West and North East Thames Regions similarly found that inner London behaved differently from the remainder of these two Regions in the relation between socioeconomic group characteristics of the population and bed use. Inner London had a higher than expected proportional bed use in the lower socioeconomic groups compared with that in the Region as a whole, or in outer London or the Home Counties. ${ }^{20}$ The divergence between inner London and the rest of the English Districts in the relation between their SMRs and their degree of deprivation indicates a prima facie, but in no sense proven, case for including social variables in the 
RAWP formula in addition to SMRs; suitable variables would include the degree of overcrowding, single parent families, elderly people living alone, ethnic minorities and residential mobility, but not those reflecting material disadvantage such as the unemployment rate and, to a lesser degree, the proportion of unskilled workers. However, this interpretation of the relations observed begs the question of whether, and if so how, features of areas such as the degree of overcrowding, affect the need for hospital and community health service resources in ways which are not reflected in morbidity or mortality rates. A frequently used hypothetical illustration of the direct effect of deprivation on the need for hospital care is the likelihood that people living in poor housing will stay in hospital longer for a given severity of a condition than non-deprived people, thus requiring more bed days. However, research on the determinants of hospital utilisation undertaken for the NHS Management Board review of national RAWP found little evidence that lengths of stay were longer in more deprived compared with less deprived small areas. ${ }^{14}$ Very few studies have incorporated the sort of detailed research at local level required to ascertain how the health care resource needs of deprived people differ from the non-deprived. ${ }^{2122}$ This, in turn, raises the question of whether the health related problems of deprivation merit remedial action by the hospital and community health services, or through the primary care system (which is not covered by the RAWP system of resource allocation), or indeed, through actions which are outside health care altogther.

The results can equally plausibly be interpreted as showing, by contrast, that in inner London, despite high levels of deprivation as measured by two Census based indices, the need for health care resources as measured by SMRs is lower than would be predicted from the relation between SMRs and deprivation in other parts of the country. This interpretation based on a concept of need in terms of ill health raises the possibility that the social indicators comprising the Jarman 8 UPA score and Townsend index (eg, households without access to a car) may represent different phenomena in different parts of the country and may not necessarily indicate need in a consistent way. For example, people have the choice not to own a car in central London without this necessarily affecting their quality of life. Thus not owning a car is less likely to be an indicator of low income and poor access to health care in central London, where public transport is highly developed, than in a rural area where it may be essential for participation in normal everyday life. The ethnic minority variable in the Jarman 8 UPA score is another indicator which may vary in validity between different parts of the country. Since there is no direct question on ethnic origin in the
Census the indicator is defined as the proportion of the population resident in households headed by someone born in the New Commonwealth and Pakistan (NCWP). As a result, second generation members of ethnic minorities originating in the NCWP are likely to be underrepresented and the NCWP population inflated in places which receive a larger proportion of the immigrant NCWP population, such as London. ${ }^{23}$ The Jarman 8 UPA score also includes a measure of residential mobility which is hard to interpret in this context. It is possible that the high rate of residential mobility observed in inner London poses particular problems for the delivery of selected community health services and thereby increases the costs incurred by inner London Districts in discharging their responsibilities. On the other hand, the inner London areas where people change address frequently are also affluent areas of rapid "gentrification".

The observed relation between SMRs and deprivation with its characteristic inner London/the rest split may be explained by reference to the independent effect of other confounding variables. There are at least two potential hypotheses of this type. Firstly, the lower SMRs but higher deprivation $\overrightarrow{0}$ recorded in inner London could be the result of the्ष $\vec{\circ}$ relatively high level of health care provision available 2 in the capital in the past. Under this hypothesis, SMR are seen as measures of the outcome of health care rather than measures of need for health care. One $\mathbb{D}$ implication of this hypothesis is that the removal of $\vec{b}$ resources through RAWP redistribution would be detrimental to the health of inner London. ${ }^{24}$ Secondly, the observed relation between SMRs and deprivation could be explained by environmental or climatic factors operating outside London and independent of the current socioeconomic conditions as measured by deprivation indices based on the 1981 Census. For example, hardness of water is known to have a protective effect on coronary heart disease. The incidence of the disease is lower among people who have live predominantly in hard water areas. ${ }^{25}$

Although the above explanations are plausible to varying degrees, it seems unlikely that the substantial and long established differences in mortality experience between geographical areas in England are the result of the relative availability of health care. Inner London Districts have a range of above and below average SMRs set against a relatively high level of health services expenditure. By contrast, inner Liverpool has enjoyed levels of health services expenditure comparable to inner London and yet experiences high SMRs. Aside from these crude observations, there appears to be no consensus among econometricians as to whether the level of spending in an area bears any discernable relation to the mortality rates and overall health status of the population. ${ }^{26-32}$ 
Reviewing the literature, Maynard concludes that the evidence in support of a clear association between higher spending and better health is not strong. ${ }^{33}$ Thus, mortality rates at a population level would seem unlikely to be a reflection of the outcome of health services intervention and remain useful proxies for need.

The hypothesis that the incidence of certain diseases may be higher in particular Regions outside London independent of prevailing socioeconomic conditions, and that this explains in part their higher SMRs, reflects the original thinking which lay behind the choice of mortality data in the national RAWP formula. Need was defined in epidemiological terms as the level of morbidity in a population irrespective of socioeconomic variables. Mortality was taken to be a reasonable proxy for morbidity. Viewed in this way, the persistently higher SMRs in the north and west of the country are appropriately included in the formula since they reflect the higher incidence of disease in those parts of the country. However, even if it is accepted that SMRs are adequate proxies for morbidity, this would not necessarily answer criticisms of RAWP based on a broader model of the need for health care resources than that adopted by RAWP. This model would include the independent effect of socioeconomic factors on needs other than health status and appears to underly the approach of the recent NHS Management Board review of national RAWP. ${ }^{14}$ The review has questioned whether the existing RAWP formula adequately takes account of social deprivation. The original RAWP model and the more recent approach are set out schematically in figs 7 and 8 . The elaborated model, which appears to

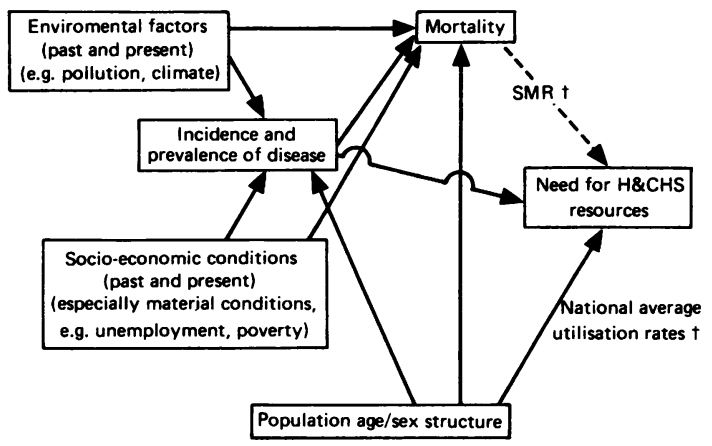

$\dagger \quad$ Needs variables included in the national RAWP formula - Proxy measure of morbidity

Fig 7 Determinants of need for hospital and community health services ( $H \& C H S$ ) resources: 1976 RAWP model

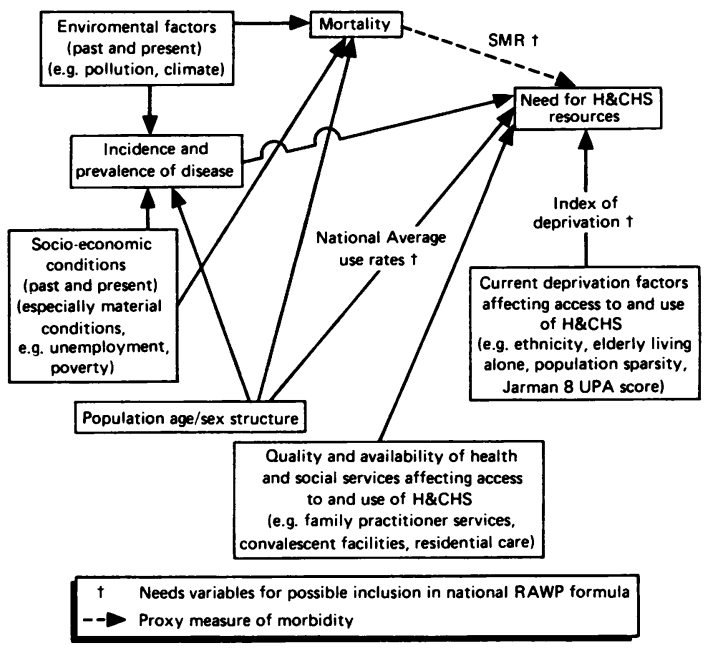

Fig 8 Determinants of need for hospital and community health services ( $H \& C H S$ ) resources: elaborated "deprivation model"

inform the NHS Management Board review, requires that account be taken of the confounding effects of the quality and availability of primary care, convalescent and residential services on the need for hospital and community health service resources before it is possible to establish the level of need generated by deprivation. A further complication is the need to determine whether the extra costs per patient which may be incurred in deprived as against non-deprived areas result from the needs of the deprived or from inefficiencies and differences in management style in the operation of local services.

The search for more broadly based measures of need for inclusion in RAWP has focused mainly on composite measures derived from the 1981 Census. For example, the Jarman 8 UPA score has been widely canvassed for this purpose (and hence its inclusion in this study), despite the fact that it was constructed to measure demand for GP services not the need for the hospital and community health services covered by RAWP. However, the analysis in this paper has prompted questions about the meaning in different parts of the country of the variables from which these composite indices are constructed. These variables were not specifically designed for Health Service use and are highly restricted in scope. For example, there is no question in the Census about income or wealth. The limited range of variables is reflected in the very high correlation between District Jarman UPA scores and District scores on the Townsend Index of Material Deprivation (correlation coefficient 0.88 ) despite the fact that the two scores were constructed differently 
and designed to measure different socioeconomic phenomena. ${ }^{34}$ On both the Jarman 8 UPA score and the Townsend index, nine of the 12 most deprived Districts are in inner London. By contrast, none of the 30 Districts with the highest SMR is in inner London (see fig 3, for example). This result suggests that, at least in terms of Health Service resource allocation, conventional deprivation variables from the Census and their composites may be inappropriate as a basis for measuring relative need for a process of national resource allocation. The Census deprivation variables would seem not only to be restricted in range, but also peculiarly sensitive to many features associated with inner London which may or may not be indicators of the need for additional hospital and community health service resources.

There are also practical problems in using data from the 1981 Census in RAWP. Firstly, it is highly likely that circumstances have changed since 1981 and by 1991 the 1981 Census will be highly misleading. Secondly, use of Census data in RAWP will lead to an abrupt shift in the pattern of allocations when data from the 1991 Census replace 1981 data. ${ }^{35}$

Carr-Hill has encouraged consideration of other sources of more up to date, more relevant, socioeconomic data than the 1981 Census. ${ }^{36}$ Both the General Household Survey and the Labour Force Survey collect annual data on socioeconomic circumstances for samples of the population large enough to analyse at Regional level. Other sources of data on material resources, available at lower levels of aggregation, are DHSS statistics on claimants in receipt of income support and Department of Employment current and long term unemployment rates, which are produced quarterly. Carr-Hill contends that the use of such variables in an index of deprivation would produce a very different ranking of Districts compared with indices based exclusively on the 1981 Census. In turn, changes to RHA or DHA rankings are likely to have substantial resource implications if deprivation weights are included in national or sub-Regional RAWP.

\section{Conclusions}

A simple correlation study such as the one presented in this paper cannot be expected to resolve such a complex and contentious issue as the choice of an appropriate needs weighting for RAWP. However, the analysis has served to raise a number of important questions about the wisdom of using national Census data to broaden the needs weighting in RAWP to include the effects of deprivation. There appears to be no merit in producing deprivation indices, however sophisticated methodologically, if they are based on inappropriate, out of date variables from the 1981
Census. Other more up to date and more direct measures of health related deprivation accompanied by regular, large scale community morbidity surveys such as the recent Health and Lifestyle survey, ${ }^{37}$ must be developed if the RAWP formula is to be refined in a way which is acceptable to all parts of England.

Our thanks are due to Gwyn Bevan, Marian Craig, Myfanwy Morgan and Charles Price for helpful comments on earlier drafts of this paper. The authors are supported by the Department of Health and Social Security.

Address for correspondence and reprints: $\mathrm{Mr} \mathrm{N} \mathrm{B}$ Mays, Department of Community Medicine, United Medical and Dental Schools of Guy's and St Thomas' Hospitals, St Thomas' Campus, London SE1 7EH, UK.

\section{References}

${ }^{1}$ Department of Health and Social Security. Sharing resources for health in England: Report of the Resource Allocation Working Party. London: HMSO, 1976.

2 Buxton MJ, Klein RE. Allocating health resources: $\vec{\Phi}$ commentary on the report of the Resource Allocation $\bar{\Phi}$ Working Party. Research Paper No. 3, Royal Commission on the National Health Service. London: HMSO, 1978.

${ }^{3}$ Forster DP. Mortality, morbidity and resource allocation. Lancet 1977; i: 997-9.

${ }^{4}$ Ferrer HP, Moore A, Stevens GC. The use of mortalityo $\overrightarrow{0}$ data in the report of the Resource Allocation Working $\stackrel{\odot}{\circ}$ Party (HMSO) 1976). Public Health 1977; 91: 289-95.

${ }^{5}$ Snaith AH. Subregional resource allocations in the National Health Service. J Epidemiol Community Health 1978; 32: 16-21.

${ }^{6}$ Forster DP. The relationships between health needs, socio-environmental indices, general practitioner resources and utilisation. J Chronic Dis 1979; 32: 333-7.

${ }^{7}$ Avery-Jones F. The London hospitals' scene. Br Med J 1976; ii: 1046-9.

8 Brennan ME, Clare PH. The relationship between mortality and two indicators of morbidity. $J$ Epidemiol Community Health 1980; 34: 134-8.

${ }^{9}$ Brennan ME, Lancashire R. Association of childhood mortality with housing status and unemployment. $J$ Epidemiol Community Health 1978; 32: 20-33.

${ }^{10}$ Carstairs V. Multiple deprivation and health state. Community Med 1981; 3: 4-13.

11 Townsend P, Phillimore P, Beattie A. Health and deprivation: inequality and the north. London: Croom Helm, 1988.

12 Mays N, Bevan G. Resource allocation in the Health Service: a review of the methods of the Resource Allocation Working Party (RAWP). London: Bedford Square Press, 1987.

${ }^{13}$ Department of Health and Social Security. Review of the Resource Allocation Working Party Formula. Report by the NHS Management Board. London: DHSS, 1986.

${ }^{14}$ Department of Health and Social Security. Review of the Resource Allocation Working Party Formula. Final Report by the NHS Management Board. London: DHSS, 1988. 
${ }^{15}$ Holland WW. The RAWP review: pious hopes. Lancet 1986; ii: 1087-90.

16 Jarman B. Identification of underprivileged areas. $\mathrm{Br} \mathrm{Med}$ $J$ 1983; 286: 705-9.

17 Morgan M, Mays N, Holland WW. Can hospital use be a measure of need for health care? J Epidemiol Community Health 1987; 41: 269-74.

18 Jarman B. Underprivileged areas: validation and distribution of scores. $\mathrm{Br}$ Med J 1984; 289: 1587-92.

19 Blaxter M. Evidence on inequality in health from a national survey. Lancet 1987; ii: 30-3.

${ }^{20}$ North West Thames Regional Health Authority. Hospital in-patient census 1981: analysis of the data. London: North West Thames Regional Health Authority, undated.

${ }^{21}$ Skrimshire A. Area disadvantage, social class and the health service. Oxford: University of Oxford, Social Evaluation Unit, Department of Social and Administrative Studies, 1978.

22 Carstairs V, Patterson PE. Distribution of hospital patients by social class. Health Bull 1966; 24: 59-67.

23 Carr-Hill R, Eastwood A, Stephenson P. Resource allocation review [Letter]. Lancet 1988; ii: 168.

24 Balarajan R. On the state of health in inner London. $\mathrm{Br}$ Med J 1986; 292: 911-4.

${ }^{25}$ Dudley EF, Beldin RA, Johnson BC. Climate, water hardness and coronary heart disease. J Chronic Dis 1969; 22: 25-48.

${ }^{26}$ Fuchs VR. Some economic aspects of mortality in developed countries. In: Perlman M, ed. The economics of health and medical care. London: Macmillan, 1974.

${ }^{27}$ McKeown T. The modern rise of population. London: Edward Arnold, 1976.
${ }^{28}$ Newhouse JP, Friedlander LJ. The relationship between medical resources and measures of health: some additional evidence. J Human Resources 1979; 15: 200-18.

${ }^{29}$ Organisation for Economic Cooperation and Development. Financing and delivering health care. Paris: OECD, 1987.

${ }^{30}$ Hadley J. More medical care, better health? An economic analysis of mortality rates. Washington DC: The Urban Institute Press, 1982.

${ }^{31}$ Auster R, Leveson I, Sarachek D. The production of health: an exploratory study. J Human Resources 1969; 4: 411-36.

32 Williams RL. Explaining a health care paradox. Policy Sciences 1975; 6: 91-101.

33 Maynard A. The production of health and health care. Health Care Management 1986; 1: 17-25.

34 Townsend P. Deprivation. J Social Policy 1987; 16: 125-46.

${ }^{35}$ Carr-Hill RA. Revising the RAWP formula: indexing deprivation and modelling demand. Discussion Paper, 41. York: University of York, Centre for Health Economics, 1988.

${ }^{36}$ Carr-Hill RA. Health status, resource allocation and socioeconomic conditions: interim report of Health Needs Research Study. York: University of York, Centre for Health Economics, 1987.

${ }^{37}$ Cox BD, Blaxter M, Buckle ALJ, et al. The health and lifestyle survey: preliminary report of a nationwide survey of the physical and mental health, attitudes and lifestyle of a random sample of 9,003 British adults. Cambridge: Health Promotion Research Trust, 1987.

Accepted for publication January 1989 